\title{
REFORMULAÇÃO CURRICULAR E ESPACIAL EM UM CURSO DE ARQUITETURA E URBANISMO
}

\author{
CURRICULAR AND SPATIAL REFORMULATION OF AN ARCHITECTURE AND URBANISM \\ COURSE
}

\author{
Dander Ribeiro Pereira Filho ${ }^{1}$ \\ Disabela Castilho Gomes de \\ Souza ${ }^{2}$ \\ (iDodrigo Tannus Fonseca ${ }^{3}$ \\ 1 Instituto Federal Fluminense, Campos \\ dos Goytacazes, RJ, Brasil. \\ zander.filho@iff.edu.br \\ 2 Instituto Federal Fluminense, Campos \\ dos Goytacazes, RJ, Brasil, \\ isabelacastilho.contato@gmail.com \\ 3 Instituto Federal Fluminense, Campos \\ dos Goytacazes, RJ, Brasil, \\ arq.rodrigotannus@gmail.com
}

Contribuição dos autores:

ZRPF: conceituação, curadoria de dados, análise formal, investigação, metodologia, administração de projetos, supervisão, validação, visualização, escrita - rascunho original, escrita - revisão e edição. ICGS: conceituação, curadoria de dados, análise formal, investigação, metodologia, validação, visualização, escrita - rascunho original, escrita - revisão e edição. RTF: conceituação, curadoria de dados, análise formal, investigação, metodologia, visualização, escrita - rascunho original, escrita - revisão e edição.

Fomento: Conselho Nacional de Desenvolvimento Científico e Tecnológico Declaração de conflito: nada foi declarado.

Editor(es) Responsável: Rafael Urano de Carvalho Frajndlich (D)

\begin{abstract}
Resumo
O curso de Arquitetura e Urbanismo do Instituo Federal Fluminense (IFF) finalizou em 2020 a reformulação do seu Projeto Pedagógico do Curso (PPC). Entre os vários parâmetros avaliados, destaca-se a inserção de Tecnologias de Informação e Comunicação (TIC), interdisciplinaridade, atualização de conteúdos e reformulação espacial. Diante desse desafio, o objetivo visa apresentar os produtos de duas pesquisas realizadas paralelamente que auxiliaram nessas reformulações. Os procedimentos metodológicos utilizados foram a revisão bibliográfica e pesquisa exploratória. A primeira pesquisa desenvolveu um método de análise das disciplinas. A segunda pesquisa propôs uma nova distribuição espacial do pavimento utilizado pelo curso. Os resultados destes trabalhos se entrelaçaram ao processo oficial da reformulação curricular, sendo capaz de influenciar nas tomadas de decisões. As análises da primeira pesquisa colaboraram para a inserção do Building Information Modeling (BIM), Realidade Virtual, Realidade Aumentada, Design Generativo, Design Paramétrico, Programação Visual, Prototipagem Rápida e Fabricação Digital nas novas disciplinas de Expressão e Representação Gráfica. Contribuíram para a integração de disciplinas com maior relação interdisciplinar. Fizeram com que 31 disciplinas mudassem sua posição na matriz, 37 alterassem seus pré-requisitos, 74 revisassem suas ementas e que 25 se unisse a outras disciplinas, evitando conteúdos sobrepostos. 9 disciplinas se tornaram optativas e 74 atualizaram sua bibliografia. Os produtos da segunda pesquisa, influenciaram na reforma do pavimento do curso, realizadas para atender às novas demandas curriculares. Conclui-se que os produtos destas pesquisas se demonstraram significativos para a mudança curricular do referido curso, sendo capaz, também, de auxiliar em outras reformulações curriculares.
\end{abstract}

Palavras-chave: Reformulação Curricular. Reformulação Espacial. Ensino. Arquitetura e Urbanismo. Interdisciplinaridade.

\begin{abstract}
The Fluminense Federal Institute Architecture and Urbanism concluded its Pedagogical Course Project (PPC) of the Architecture and Urbanism course in 2020. Among the various evaluated parameters, the insertion of Information and Communication Technologies (ICT), the interdisciplinarity and updating of contents, and spatial readjustment stand out. This paper aims to present how the products of two studies performed in parallel helped in this reformulation. The methodologies were bibliographical and exploratory research. The first study developed a method for analyzing curricular components. The second research proposed a new spatial distribution of the building floor used by the course. The results were intertwined with the official curriculum reformulation process influencing decision-making. The first research analysis contributed to the insertion of BIM (Building Information Model), Virtual Reality, Augmented Reality, Generative Design, Parametric Design, Visual Programming, Rapid Prototyping, and Digital Manufacturing, the new disciplines of Expression and Graphic Representation. They have contributed to the integration of disciplines with a greater interdisciplinary relationship. They made 31 disciplines change their position in the matrix, 37 change their prerequisites, 74 review their menus, and 25 join other disciplines, avoiding overlapping content. Nine subjects became optional, and 74 updated their bibliography. The second research product influenced the Course's pavement reform, conducted to meet the new curricular demands. It is concluded that the products of these researches were significant for the curricular change, assisting in the other curricular reformulations.
\end{abstract}

Keywords: Curricular Reformulation. Spatial Reformulation. Architecture and Urbanism.

Technology. Interdisciplinarity.

How to cite this article:

PEREIRA FILHO, Z. R.; SOUZA, I. C. G. de; FONSECA, R. T.. Reformulação curricular e espacial em um curso de arquitetura e urbanismo. PARC Pesquisa em Arquitetura e Construção, Campinas, SP, v. 12, p. e0210xx, 2021. DOI:

http://dx.doi.org/10.20396/parc.v12i00.8660009

Submitted 11.06.2020 - Approved 02.02.2021 - Published 01.07.2021

e021012-1 | PARC Pesq. em Arquit. e Constr., Campinas, SP, v. 12, p. e021012, 2021, ISSN 1980-6809 


\section{Introdução}

Desde a consolidação da era da informação no final do século XX, as Tecnologias de Informação e Comunicação (TIC) dão suporte a vida humana, de forma a produzir, armazenar, transmitir e simular a informação (LÉVY, 2004). Entretanto, pode-se observar um intervalo de aproximadamente dez anos entre a comercialização e a adoção em massa de uma nova tecnologia pela sociedade (JOHNSON, 2011).

Quando comparados, o tempo de adaptação e adoção do mercado, ao das instituições de ensino, as segundas demonstram dificuldades estruturais para se manterem no ritmo de atualizações constantes e incorporarem as inovações à medida que já são exigidas pelo mundo do trabalho.

Além da necessidade de incorporar novas tecnologias, na era de progressos rápidos e contínuos, o mundo do trabalho espera um perfil profissional adequado a este tempo. O desafio deste momento histórico é formar sujeitos criativos, críticos, reflexivos, colaborativos e capazes de trabalhar em grupo, resolvendo problemas reais, integrando prática e teoria.

Empresas e escolas têm adaptado seu ambiente para que este esteja propício à criatividade, sem receio do experimental; com diminuição da hierarquia (tendência a horizontalidade), aniquilação de práticas autoritaristas e democracia direta.

Diante desse cenário, o curso de Arquitetura e Urbanismo do Instituto Federal Fluminense (IFF), concluiu no ano de 2020, a reformulação do seu Projeto Pedagógico de Curso (PPC) a fim de proporcionar novas experiências didático-pedagógicas aliadas às necessidades tecnológicas, interdisciplinares e, consequentemente, a reformulação de seus espaços físicos.

Nessa perspectiva, as TIC's aparecem como possibilidades viáveis, pois se mostram capazes de auxiliar na integração de disciplinas, entre outras possibilidades. Porém, entende-se que somente $a$ inserção delas são insuficientes para o pensar interdisciplinar, sendo necessário suporte de conceitos mais consistentes.

Neste sentido, o objetivo desse artigo visa apresentar a influência de duas pesquisas científicas nas tomadas de decisões da reformulação curricular e espacial do referido curso. A metodologia utilizada nesse trabalho consistiu na revisão bibliográfica e pesquisa exploratória na matriz do curso. Essas pesquisas aconteceram em momentos distintos e se entrelaçaram ao final desse processo, entre os anos de 2019 e 2020.

A primeira pesquisa aconteceu entre 2014 a 2018, sendo aplicada em 2019, onde foi desenvolvido um método de análise dos componentes curriculares. A segunda pesquisa, desenvolvida em 2019, propôs readequações nos espaços internos do pavimento ocupado pelo curso a partir de conceitos cibernéticos.

Os resultados alcançados pelo método de análise, demonstraram quais TIC's podem ser implementadas no curso. Assim como, quais disciplinas deveriam mudar sua posição da matriz, alterar os pré-requisitos, rever as ementas, se unir a outras disciplinas, se tornar optativas e/ou atualizar sua bibliografia. Os resultados da segunda pesquisa, sugeriram espaços multifuncionais que privilegiassem a pluralidade, a diversidade e a flexibilidade.

Por fim, os produtos dessas pesquisas associadas, se demonstraram significativos para a elaboração da nova proposta curricular, sendo aplicados, na medida do possível, considerando o contexto do curso. Sendo assim, entende-se que este trabalho possa auxiliar em outras reformulações curriculares, dada às necessidades atuais do nosso momento histórico. 


\section{O ensino de arquitetura e os avanços tecnológicos}

O século XXI tem sua produção de riqueza fortemente relacionada a produção do conhecimento, com ciclos de desenvolvimento cada vez menores (RIES, 2012), focados em um processo de aperfeiçoamento com atualizações contínuas e rápidas. Essa mudança no equilíbrio sistêmico, com drásticas implicações sociais e econômicas, instiga novas relações na preparação/produção de trabalhadores e pesquisadores a nível global.

Pieter Schreurs, em entrevista à Sedrez (2015), afirma que, se novas habilidades são esperadas dos arquitetos, é necessário discutir estratégias de formação profissional, capacitação tecnológica dos professores e, consequentemente, reestruturação curricular dos cursos (BARISON, 2015). Em entrevista, sumarizada em Mori (2019), Jeniffer Groff acrescenta que o pensamento crítico, a criatividade, a colaboração e a comunicação são as quatro principais competências exigidas pelas novas dinâmicas do trabalho neste século.

Afetada por uma herança Positivista do século XIX (JAPIASSÚ, 1976), que fragmentou os conteúdos acadêmicos e, uma formação tecnicista voltada para Era Industrial, a educação tradicionalmente empregada no ensino superior brasileiro tende a valorizar a quantidade de créditos, disciplinas e tarefas em detrimento da qualidade. Evidências científicas a respeito do desenvolvimento do pensamento divergente, precursor da habilidade criativa (AGOGUÉ, 2014), também são ignoradas pela configuração do cenário atual, que não dá espaço para momentos "task negative", os quais são capazes de aumentar o desempenho durante atividades de foco (task positive).

Além do ensino de arquitetura e urbanismo apresentar dificuldades no resgate das práticas interdisciplinares intrínsecas à função (KOLAREVIC, 2003) desde Vitruvius, com a visão do arquiteto generalista, dotado de versatilidade e capaz de situar e articular problemas complexos, ainda está defasado no que tange às demandas do mundo do trabalho e a incorporação inter e/ou transdisciplinar das TIC's. Os algoritmos e a robótica vão mudar drasticamente o processo de design e construção (ALLEN, 2016), tornando a programação um instrumento consolidado de projeto.

A programação, tanto textual quanto visual, só é possível no campo da arquitetura pelo desenvolvimento e adoção de práticas de design computacional, isto é, a projetação lógica e matemática. É importante destacar que esse termo não implica, necessariamente, no uso do computador como ferramenta, e a sistematização do design arquitetônico é explícito desde o pensamento de Alberti, no Renascimento (COLI, 1983). Os aplicativos e algoritmos personalizados apenas automatizam e facilitam a parametrização do design, a aplicação de sistemas generativos ou análises formais como a gramática da forma, mas a definição mais fundamental desses termos não é dependente da automação.

O uso de softwares específicos eleva o Design Paramétrico (DP) a um outro nível, permitindo a associatividade entre elementos projetuais, geométricos ou não, de forma que a cada manipulação do design, o redesenho em todas as instâncias, representações e extração de dados afetados é feito em tempo real, automaticamente (HANAFIN; PITTS; DATTA, 2009). Já na abordagem do Design Generativo (DG), em vez de criar um design estático, o arquiteto é responsável pela montagem do sistema gerador de soluções, os quais são capazes de gerar milhares de alternativas ótimas para um mesmo problema.

A Gramática da Forma (GF), por sua vez, é uma estrutura computacional capaz de descrever um sistema formal por meio de regras (transformações euclidianas) e um 
vocabulário (formas geométricas), sendo um forte método analítico. Baseada no sistema do matemático Emil Post e na gramática generativa do linguista Noam Chomsky, a principal crítica à GF é sua limitação formalista que analisa apenas os aspectos gramaticais das composições, ignorando semântica e funcionalidade (CELANI et al, 2006).

Todos esses dados projetuais ficam mais fáceis de serem manipulados quando gerenciados por Modelos de Informação, como o Building Information Modeling (BIM), usado na escala do edifício, ou o City Information Modeling (CIM), modelo análogo que armazena informações de interesse na escala urbana. Esses sistemas de dados buscam incorporar diversas dimensões (tempo, custos, entre outras) aos modelos tridimensionais, permitindo gerenciar a informação de forma inteligente ao longo do ciclo de vida do projeto e automatizar processos, análises, logística de construção, renovações e/ou demolições. Os softwares BIM geralmente possibilitam o design paramétrico e caminham para a incorporação do design generativo, além da preparação dos modelos para Fabricação Digital (FD) ou Prototipagem Rápida (PR) e a exportação dos modelos diretamente para simulações de Realidade Virtual (RV) ou Realidade Aumentada (RA).

Como ferramenta de auxílio durante o processo de design, a Realidade Virtual (RV) é capaz de imergir o usuário em um ambiente sintético, substituindo totalmente a visão do mundo real por um espaço gerado por computador. Já a Realidade Aumentada (RA), disseminada pela integração com smartphones, é uma variação de realidade mista, a qual simula cenários virtuais misturando-os a elementos do mundo real. A RA pode ser definida como "um sistema que combina informação real à gerada por computador em um ambiente real, interativamente e em tempo real, alinhando objetos virtuais a objetos físicos" (HÖLLERER; FEINER, 2004, tradução nossa). Portanto, a RA suplementa a realidade, em vez de completamente substituí-la, como acontece na RV.

Os novos métodos de produção não são mecânicos, mas controlados por computador (Computer Numeric Control (CNC)) e capazes de dispensar a assistência humana. Segundo Pupo (2008), os cursos de arquitetura no exterior têm se apropriado do horizonte de possibilidades aberto por essas tecnologias em busca de maiores integrações projeto-obra. Enquanto o termo de prototipagem rápida é usado para métodos de produção de protótipos por sistemas aditivos (DE KESTELIER; BUSWELL, 2009) a fabricação digital é um termo mais genérico que também designa outros métodos de produção digital que não são baseados em sistemas aditivos, como cortadoras a jato d'água e diversos outros tipos de equipamentos CNC.

A Internet das Coisas (IoT), sigla em inglês para Internet of Things, também pode ser considerada como ferramenta projetual. Trata-se de um cenário configurado pela proliferação de dispositivos dotados de sensores e conectados à internet, causando uma sensibilidade ubíqua, capaz de medir, inferir e analisar indicadores ambientais (FAROOQ et al, 2015). Esse paradigma se baseia em um padrão de comunicação autônoma do tipo máquina-máquina (M2M), por meio de tecnologias como RadioFrequency Identification (RFID) e Wireless Sensor Networks (WSNs) (FAROOQ et al, 2015).

A crescente capacidade de processamento computacional, unida às possibilidades de input contemporâneas (como os dados coletados pela IoT), abre caminhos para novas formas de projetação também na escala urbana. Segundo o Senseable City Lab (SCL) (2020, tradução nossa), "a revolução digital está distribuindo um vasto sistema de câmeras, dispositivos de comunicação, microcontroles e sensores em nosso ecossistema, o que permite que formas completamente novas de imaginar, monitorar e compreender as cidades." 
Com a capacidade técnica de conduzir a visualização em tempo real de dados gerados por redes e sistemas urbanos, surge uma nova disciplina, Urban Data Science (UDS) (KANG et al, 2019), isto é, ciência dos dados aplicada a cidades. Considerada "[...] expansiva, integrada e interdisciplinar" (KANG et al, 2019, p. 1765), o termo que a identifica é acusado de idolatria à metodologia, já que há muitas formas de investigar um fenômeno que podem não ser quantificáveis. Como ciência é uma operação de construção teórica, a Urban Data Science se diferencia de Data Science por ser construída e construir a partir de teorias urbanísticas.

Diante de novas possibilidades de manufatura e ferramentas que dialogam diretamente com o processo criativo do espaço, a revisão das estratégias de formação do arquiteto e urbanista não é facultativa, mas obrigatória, no sentido em que aumentam as oportunidades de atuação profissional dos egressos, assim como os prepara para enfrentar os problemas socioespaciais contemporâneos com ferramentas igualmente complexas, abrangentes e em rápida atualização.

\section{O processo de reformulação curricular}

O curso de Arquitetura e Urbanismo do Instituto Federal Fluminense (IFF), Campus Campos Centro, iniciou suas atividades no ano de 2006 e, após cinco anos, obteve o reconhecimento do MEC. O IFF tornou-se a primeira Instituição da Rede Federal de Educação Profissional, Científica e Tecnológica a ter um curso superior na área reconhecido pelo MEC.

O primeiro Projeto Pedagógico do Curso (PPC) constituiu-se de 81 disciplinas obrigatórias distribuídas em 2 núcleos de conhecimentos (fundamentação e profissional) e 1 núcleo de Trabalho de Curso, além das atividades acadêmico-científicoculturais (atividades complementares) e estágio curricular supervisionado, segmentadas por 10 semestres letivos.

Após o fechamento do primeiro ciclo de formandos, em 2012, iniciaram-se discussões internas sobre a reformulação curricular. De 2012 até 2020, o curso contou com 4 coordenadores diferentes, que propuseram diversas ações como a criação de grupos de trabalho e seminários de reformulação curricular. Cada um contribuiu à sua maneira para que esta reforma fosse efetivada, o que só aconteceu, oficialmente, em 2020.

A partir das percepções das ações realizadas de 2012 a 2018, verificou-se a necessidade de compilar as informações até então produzidas, além de verificar as necessidades antes não percebidas e discutidas. Nesse sentido, serão apresentadas 2 pesquisas realizadas pelos autores desse trabalho, que se associaram ao processo de reformulação curricular a partir de 2018, conforme a seguir: (i) Análise dos componentes curriculares e (ii) Análise cibernética dos espaços físicos.

\section{Análise dos componentes curriculares}

As ideias iniciais para a análise das disciplinas partiram de um projeto de iniciação científica a fim de pesquisar, restritamente, a inserção do BIM no currículo do curso a partir dos estudos realizados por Checcucci (2014). Com o avançar do processo de reformulação curricular, verificou-se a necessidade de elaborar um método próprio que englobasse outros parâmetros curriculares para além do BIM. O método desenvolvido é composto por nove categorias, distribuídas de (a) a (i), demonstradas a seguir.

A categoria (a) analisa se a disciplina possui interface com alguma TIC, conforme apontado por Leal (2019) e outras revisões de literatura sem meta-análise como Braida et al. (2016), Pires et al. (2017), além de experiências pedagógicas experimentais, aplicadas em diversos componentes curriculares do curso; (b) relaciona uma possível 
interdisciplinaridade; (c) indica se a posição da disciplina na matriz deve ser alterada; (d) verifica se a carga-horária deve sofrer alguma modificação; (e) analisa a criação ou exclusão de pré-requisitos; (f) avalia se a ementa deve ser revista; (g) analisa se os conteúdos da disciplina estão sobrepostos aos conteúdos de outra disciplina; (h) verifica se a natureza da disciplina (obrigatória/optativa/eletiva) deve ser alterada e, por último, a categoria (i) se a bibliografia precisa ser alterada e/ou atualizada.

As categorias (a) e (b) possuem 4 opções de respostas (forte, média, fraca e nenhuma), indicando os níveis de relação, que também são demonstrados através de gradação de cores (tons de azuis). As demais categorias apresentam 3 alternativas de respostas: sim, não e talvez, também representada pela gradação de cores (tons de cinza). Esta última opção de resposta (talvez), indica que a decisão final depende do foco dado pelo professor ou outra justificativa (Figura 1).

Figura 1 - Modelo do método desenvolvido para análise das disciplinas

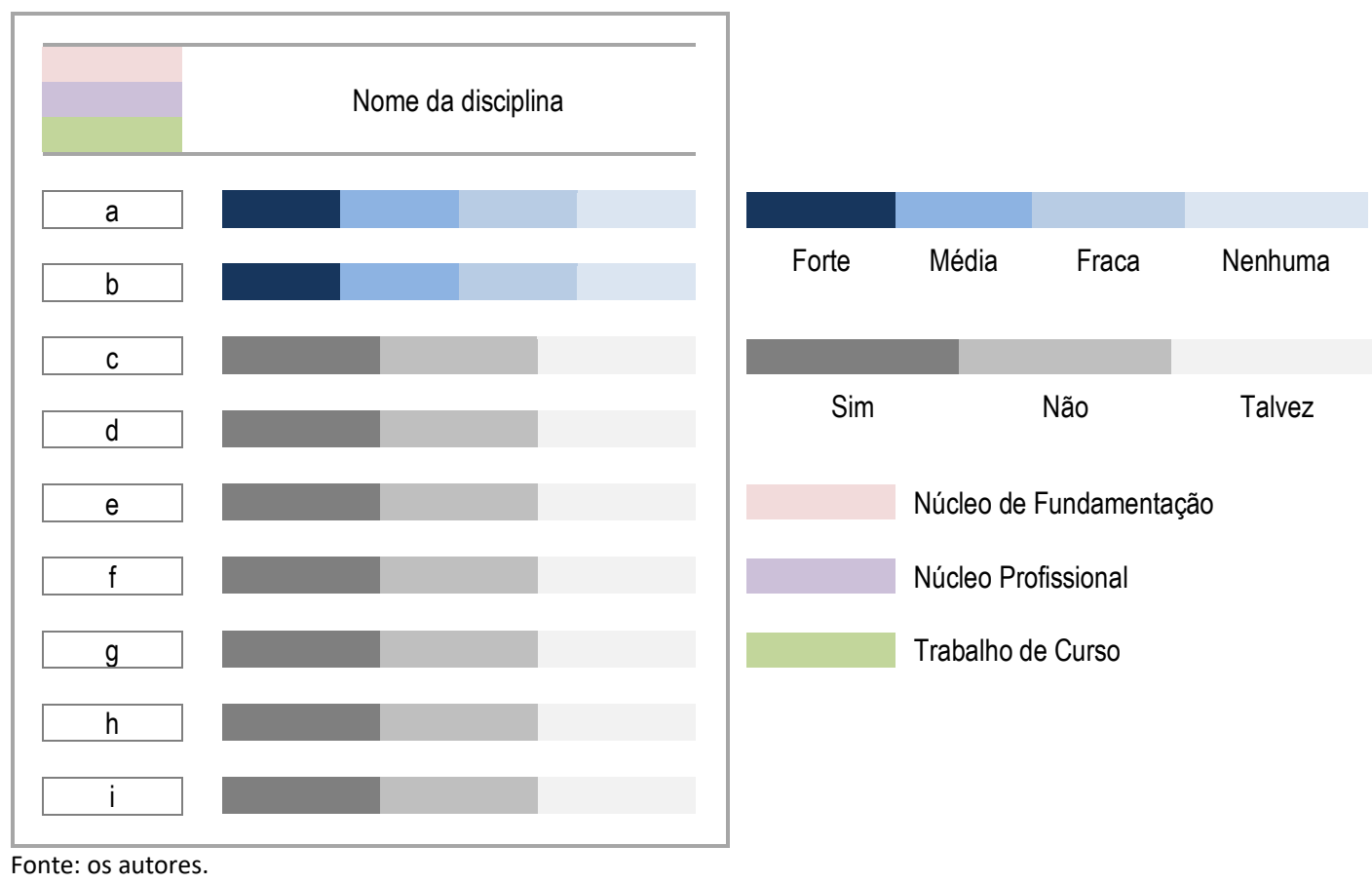

O método proposto foi aplicado através de formulários on-line e presenciais aos professores e estudantes do curso em 2019. As informações obtidas foram registradas nas caixas de análise a fim de obter uma visão sistêmica da matriz vigente. Após a compilação desses dados, iniciou-se a fase das reuniões promovidas pela coordenação do curso, com a participação de toda a comunidade acadêmica para a apresentação desses resultados. A cada debate as análises eram lapidadas, até que, em um dado momento, houve um consenso, resultando no desenho final da nova matriz. Os resultados produzidos pelo método de análise criado serão apresentados conforme a ordem das categorias.

\section{Categoria (a)}

Os produtos das análises da categoria (a) foram divididos em 3 partes, conforme 0 agrupamento dos períodos: (i) $1^{\circ}$ ao $3^{\circ}$ período; (ii) $4^{\circ}$ ao $6^{\circ}$ período; (iii) $7^{\circ}$ ao $10^{\circ}$ período. Após a apresentação das análises, serão demonstradas as TIC's que, de fato, se incorporaram ao novo PPC. Dentre elas estão os Modelos de Informação (BIM/CIM), Realidade Virtual (RV), Realidade Aumentada (RA), Prototipagem Rápida (PR), Fabricação Digital (FD), Internet das Coisas (IoT) e Ciência de Dados (CD), termo 
PEREIRA FILHO, Z. R.; SOUZA, I. C. G. de; FONSECA, R. T.

Reformulação curricular e espacial em um curso de arquitetura e urbanismo

genérico para englobar Big Data, Data Science e Data Analytics. As análises apresentadas nos Quadros 1, 2 e 3 tiveram forte impacto na revisão das ementas e, também, em possíveis relações interdisciplinares.

\begin{tabular}{|c|c|c|c|c|c|c|c|c|c|c|c|c|}
\hline & Tecnologias de Informação e Comunicação & 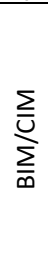 & 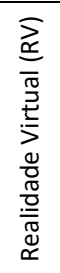 & 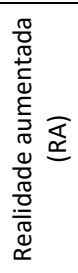 & 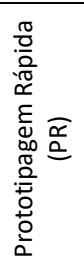 & 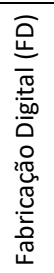 & 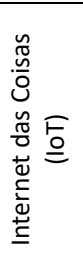 & 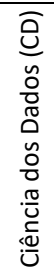 & 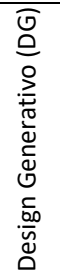 & 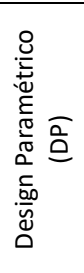 & 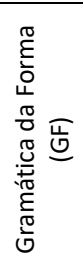 & 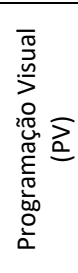 \\
\hline \multirow{10}{*}{ 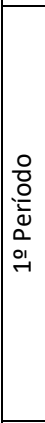 } & Desenho de Arquitetura I & & & & & & & & & & & \\
\hline & Desenho de Observação I & & & & & & & & & & & \\
\hline & Desenho Téc. E Constr. Geom. & & & & & & & & & & & \\
\hline & Estética e História da Arte I & & & & & & & & & & & \\
\hline & Estudos Soc. Econ. e Amb. & & & & & & & & & & & \\
\hline & Filosofia e Arquitetura & & & & & & & & & & & \\
\hline & Geometria Descritiva I & & & & & & & & & & & \\
\hline & Informática aplic à Arq. e Urb. I & & & & & & & & & & & \\
\hline & Matemática Básica & & & & & & & & & & & \\
\hline & Plástica I & & & & & & & & & & & \\
\hline \multirow{10}{*}{ 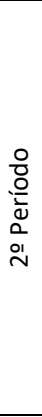 } & Cálculo Dif. e Integral & & & & & & & & & & & \\
\hline & Composição e Modelos Estrut. & & & & & & & & & & & \\
\hline & Desenho de Arquitetura II & & & & & & & & & & & \\
\hline & Desenho de Observação II & & & & & & & & & & & \\
\hline & Estética e História da Arte II & & & & & & & & & & & \\
\hline & Geometria Descritiva II & & & & & & & & & & & \\
\hline & Informática aplic à Arq. e Urb. II & & & & & & & & & & & \\
\hline & Metodologia do Trab. Científico & & & & & & & & & & & \\
\hline & Plástica II & & & & & & & & & & & \\
\hline & Urbanismo e Meio Ambiente & & & & & & & & & & & \\
\hline \multirow{8}{*}{ 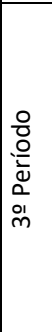 } & Conforto Ambiental I & & & & & & & & & & & \\
\hline & Informática aplic à Arq. e Urb. III & & & & & & & & & & & \\
\hline & Materiais de Construção I & & & & & & & & & & & \\
\hline & Perspectiva & & & & & & & & & & & \\
\hline & Projeto de Arq. I - Habitação I & & & & & & & & & & & \\
\hline & Sistema Estrutural I & & & & & & & & & & & \\
\hline & Teoria e História da Arq. I & & & & & & & & & & & \\
\hline & Topografia Aplic. à Arq. I & & & & & & & & & & & \\
\hline
\end{tabular}

Nos 3 primeiros períodos, as TIC's com maior interface nas disciplinas foram RV, RA, BIM/CIM e PR. Foi possível observar que as relações fracas aconteceram, em maior número, no $1^{\circ}$ período, devido ao caráter introdutório/teórico das disciplinas.

A partir do $2^{\circ}$ período, essas relações começaram a ficar mais fortes, demonstrando que essas tecnologias têm um grande potencial para auxiliar as disciplinas do núcleo de fundamentação e profissional, principalmente aquelas que trabalham com noções iniciais do espaço e da forma, além das disciplinas de informática. As disciplinas teóricas também apresentaram forte relação com as tecnologias RV e RA, em todos os períodos, dada a possibilidade de imersão virtual dos conteúdos nelas ministrados.

Os resultados obtidos do $4^{\circ}$ ao $6^{\circ}$ período, onde há grande concentração de disciplinas projetuais, indicam forte relação com as tecnologias RV, RA, BIM/CIM e PR (Quadro 2). A relação das demais tecnologias FD, IoT, CD, DG, DP, GF e PV manifesta-se de forma gradual, apresentando uma relação fraca no $4^{\circ}$ período, que se intensifica no $5^{\circ}$ período, atingindo nível forte no $6^{\circ}$ Período. 
PEREIRA FILHO, Z. R.; SOUZA, I. C. G. de; FONSECA, R. T.

Reformulação curricular e espacial em um curso de arquitetura e urbanismo

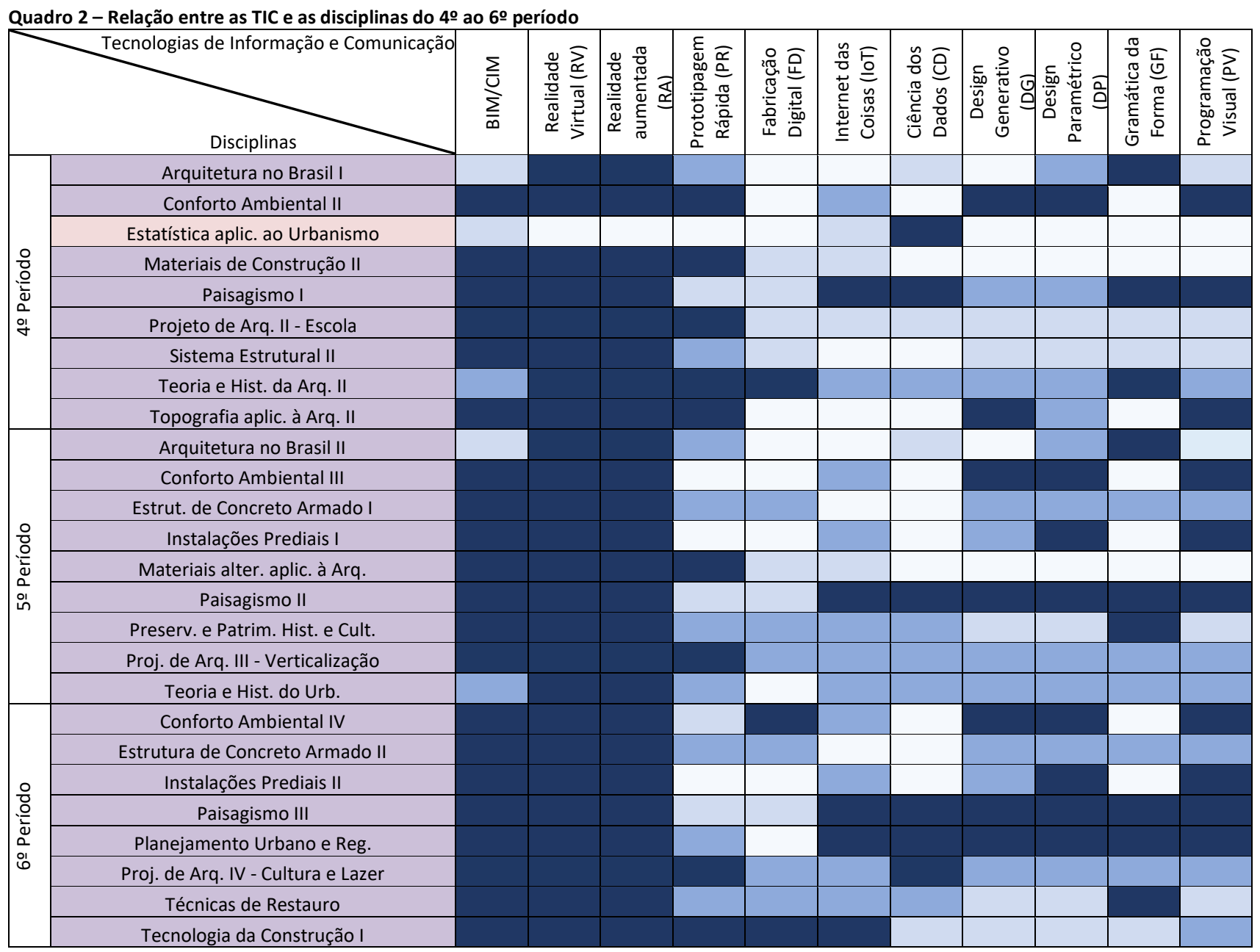

Todas as disciplinas de projeto de arquitetura possuem forte relação com as TIC's. As disciplinas de projetos urbanísticos apresentam relação forte com 9 (nove) TIC's, 1 (uma) relação média com PD e nenhuma relação com FD, devido a escala de abrangência. As disciplinas dos períodos finais exigem maior processamentos de dados e complexidade de projetos, justificando a quantidade de relações fortes.

As disciplinas que não estão ligadas diretamente a área da arquitetura (Gestão e Economia Empresarial e Empreendedorismo e Marketing) apresentaram pouca relação com as TIC's analisadas. No $9^{\circ}$ período, a disciplina de Fundamentos de TFG, obteve forte relação apenas com loT e $C D$, visto que o enfoque dela é a produção teórica. A disciplina Seminários de TFG não obteve relação com as TIC's, pois é voltada a apresentação de seminários. Por último, a disciplina de Trabalho Final de Graduação (TFG), obteve relação média, visto que o enfoque tecnológico está a arbítrio do estudante (Quadro 3).

\section{Categoria (b)}

A partir da análise da categoria (b), foram identificadas as relações interdisciplinares nos componentes curriculares da matriz 2014-1. As relações interdisciplinares fortes, resultaram na criação de disciplinas integradas na nova matriz. Disciplinas com relação interdisciplinar média, situadas no mesmo período, tornaram-se co-requisitos. As disciplinas com relação interdisciplinar fraca ou nenhuma, não interferiram significativamente nas decisões da reformulação curricular. 
PEREIRA FILHO, Z. R.; SOUZA, I. C. G. de; FONSECA, R. T.

Reformulação curricular e espacial em um curso de arquitetura e urbanismo

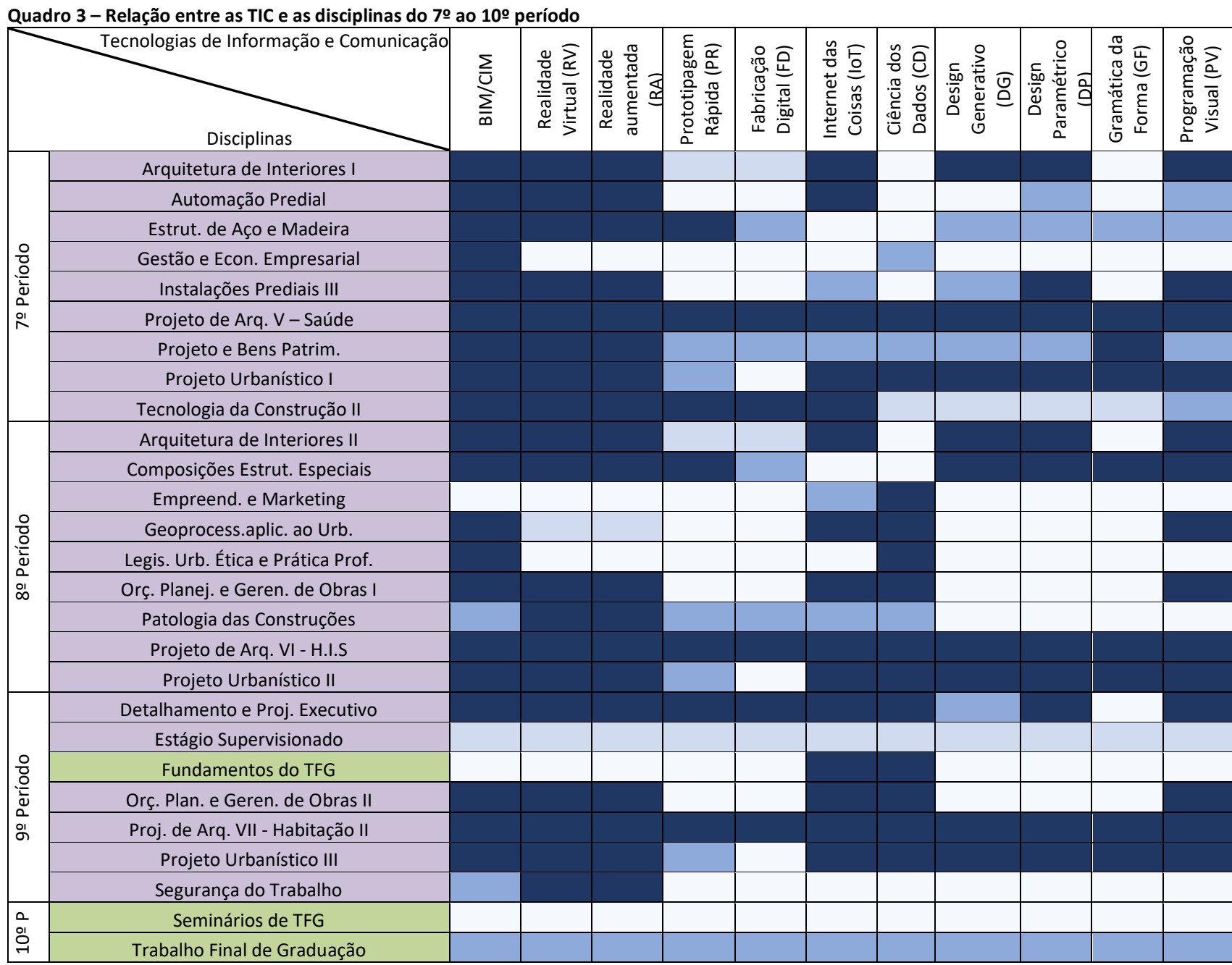

Fonte: os autores.

A Figura 2 demonstra os exemplos de forte relação interdisciplinar entre Plástica I e Desenho de Observação I ( $1^{\circ}$ período) e Plástica II e Desenho de Observação II ( $2^{\circ}$ período), ambas do núcleo de conhecimento de fundamentação da matriz antiga, que se uniram, transformando-se, na nova matriz, nas disciplinas de Observação e Composição Plástica I e II, respectivamente, no $1^{\circ} \mathrm{e} 2^{\circ}$ período do curso.

As disciplinas de Informática Aplicada à Arquitetura e Urbanismo I, Desenho de Arquitetura I e Geometria Descritiva I ( $1^{\circ}$ período) e Informática Aplicada à Arquitetura e Urbanismo II, Desenho de Arquitetura II e Geometria Descritiva II ( $2^{\circ}$ período) também tiveram forte relação interdisciplinar e seguiram a mesma lógica de fusão e criação de novos componentes curriculares integrados. Nestes casos, as disciplinas criadas na nova matriz foram: Expressão e Representação Gráfica I ( $1^{\circ}$ período) e Expressão e Representação Gráfica II ( $2^{\circ}$ período).

No núcleo de conhecimento profissionais, as relações interdisciplinares de maior impacto ocorreram nas disciplinas de Projetos de Arquitetura (Figura 3). Estas análises contribuíram para a criação de 4 novas disciplinas denominadas de Projetos Integrados, entre o $6^{\circ}$ e $9^{\circ}$ períodos. A proposta consistiu em unir os conteúdos ministrados de maneira isolada nas disciplinas de Projeto de Arquitetura, aos conteúdos de disciplinas com forte relação interdisciplinar. Assim, o planejamento das ações interdisciplinares aconteceu de maneira mais assertiva e sincronizada, visto que os professores dessas disciplinas, antes segmentadas, estavam focados no mesmo objetivo. 
PEREIRA FILHO, Z. R.; SOUZA, I. C. G. de; FONSECA, R. T.

Reformulação curricular e espacial em um curso de arquitetura e urbanismo

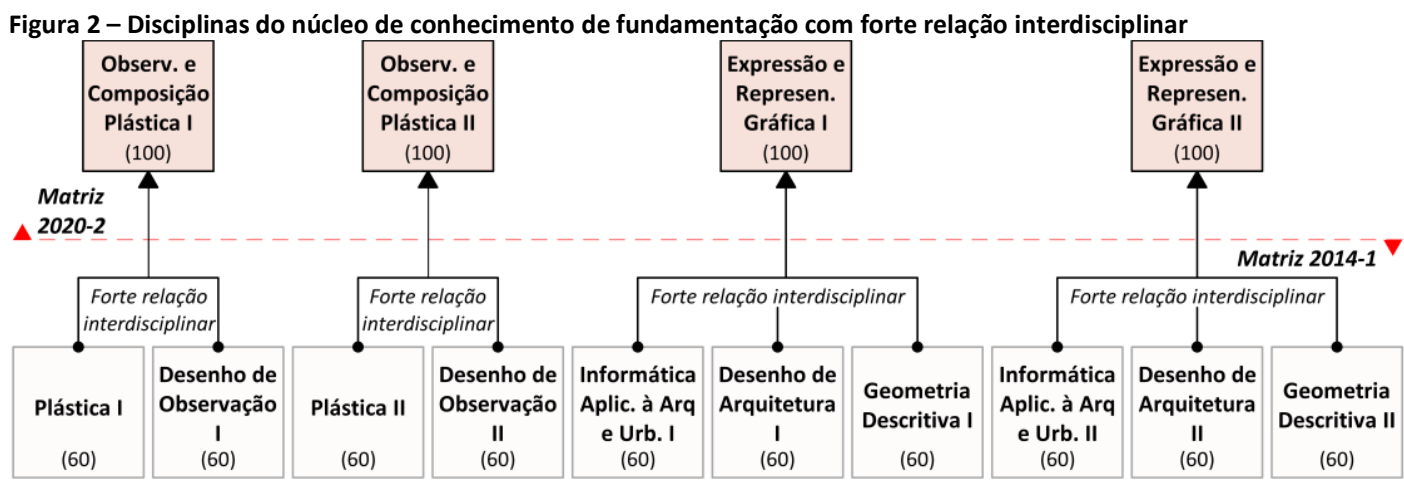

Fonte: os autores.

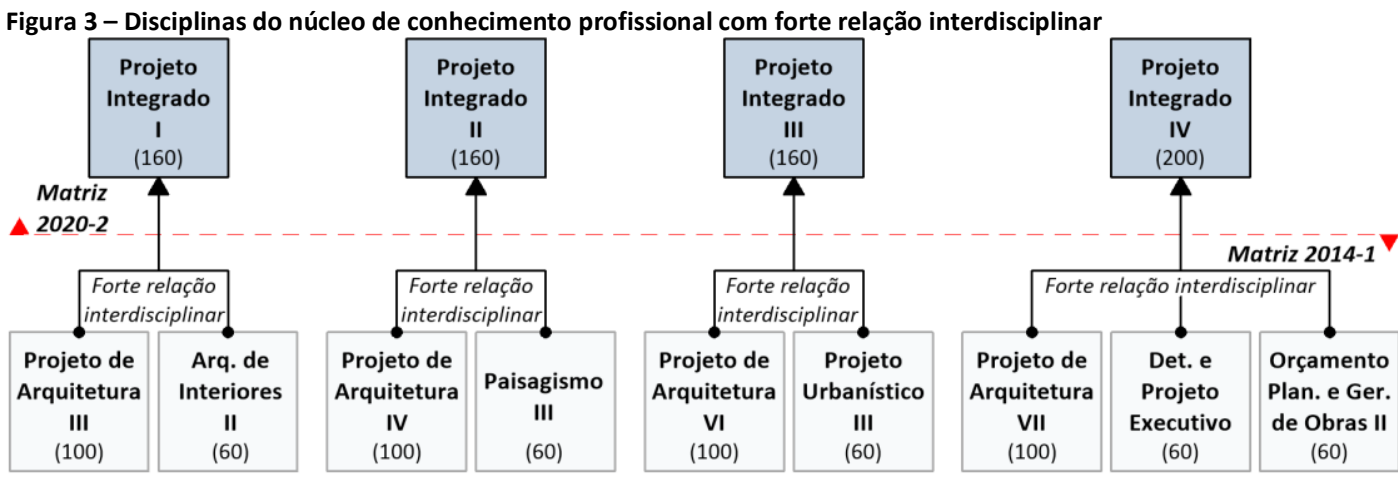

Fonte: os autores.

Na disciplina de Projeto Integrado I, o enfoque visa desenvolver projetos de edifícios mistos (comerciais e residenciais) e a arquitetura de interiores destes espaços de maneira conjunta. No Projeto Integrado II, cuja temática é Cultura e Lazer, integrou-se o projeto de arquitetura aos conteúdos de Paisagismo. No Projeto Integrado III, o Projeto de Habitação de Interesse Social foi planejado para ser aplicado em áreas urbanas já consolidadas, o que antes era realizado, de maneira isolada, na disciplina Projeto Urbanístico III.

Por último, a disciplina de Projeto Integrado IV propõe que os estudantes desenvolvam um projeto completo de arquitetura residencial unifamiliar, englobando os conteúdos das antigas disciplinas de Orçamento II e Detalhamento e Projeto Executivo. Integrações como essas, também aconteceram em outras disciplinas dos núcleos de conhecimento de fundamentação e profissional.

Categorias (c) a (i)

Os resultados das análises das categorias (c) a (i) indicaram, respectivamente, que 31 disciplinas sofressem alteração na posição original da matriz, 37 disciplinas alterassem a carga horária, 41 disciplinas alterassem pré-requisitos, 74 disciplinas revisassem conteúdos, 25 disciplinas fossem fundidas a outras, 9 disciplinas tornassem-se optativas e 74 disciplinas tivessem a bibliografia alterada e/ou atualizada (Figura 4).

Dentre os resultados apresentados na Figura 4, destaca-se a análise feita nas categorias (f) e (g). Os produtos destas análises colaboraram para que 74 disciplinas tivessem suas ementas revistas e 25 disciplinas se fundissem a fim de evitar sobreposição de conteúdos. 
PEREIRA FILHO, Z. R.; SOUZA, I. C. G. de; FONSECA, R. T.

Reformulação curricular e espacial em um curso de arquitetura e urbanismo

Figura 4 - Resultados das análises das categorias (c), (d), (e), (f), (g), (h) e (i)

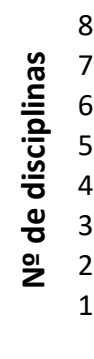

80
70
60
50
40
30
20
10
0

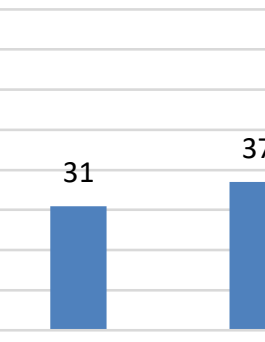

(c)

(d)

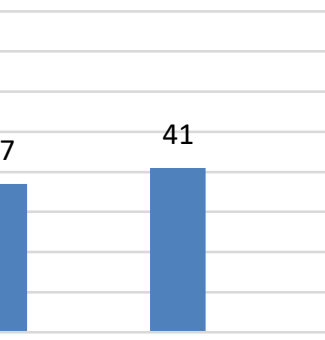

(e)

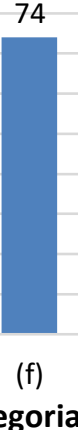

(f)

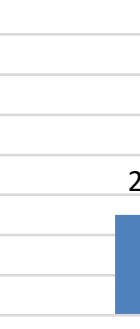

(g)

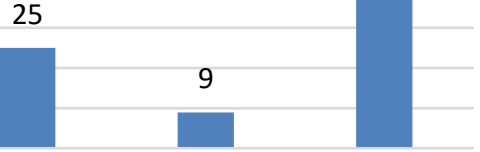

(h)

(i)

Fonte: os autores.

\section{A nova matriz}

Após as discussões dessas análises, as TIC's implementadas no novo PPC estão em destaque na Figura 5.

\section{Figura 5 - Nova matriz curricular 2020.2, destaque para as disciplinas que tiveram alguma TIC implementada}

\section{Fundamenação}

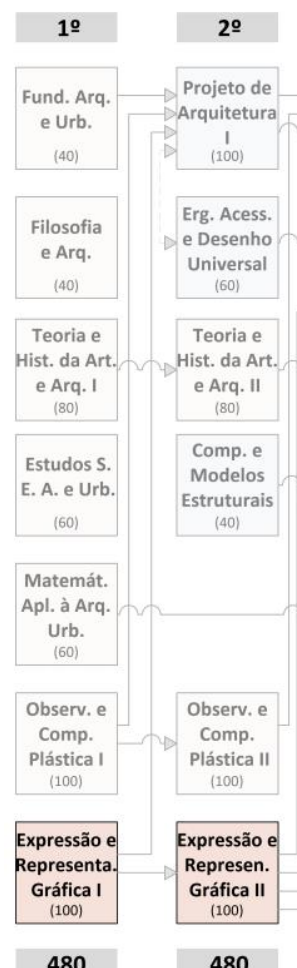

Fonte: os autores.

\section{Profissionalização}

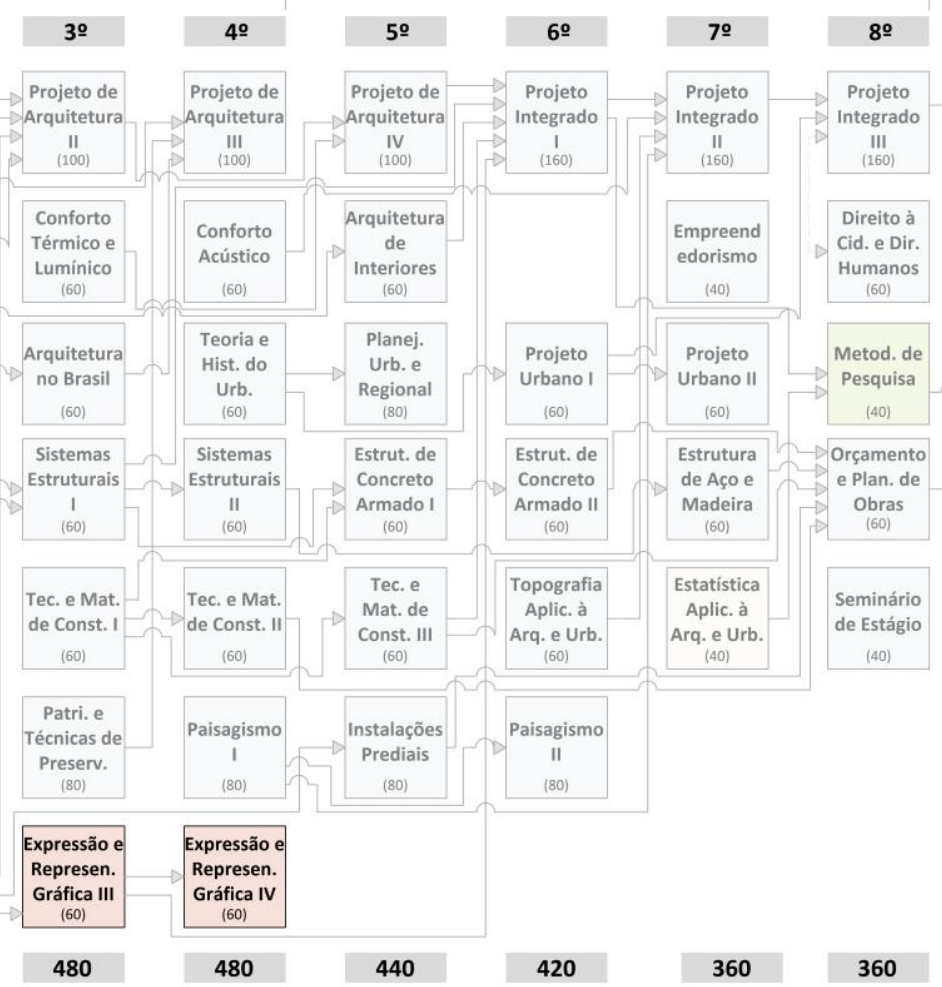

\section{Sintese}

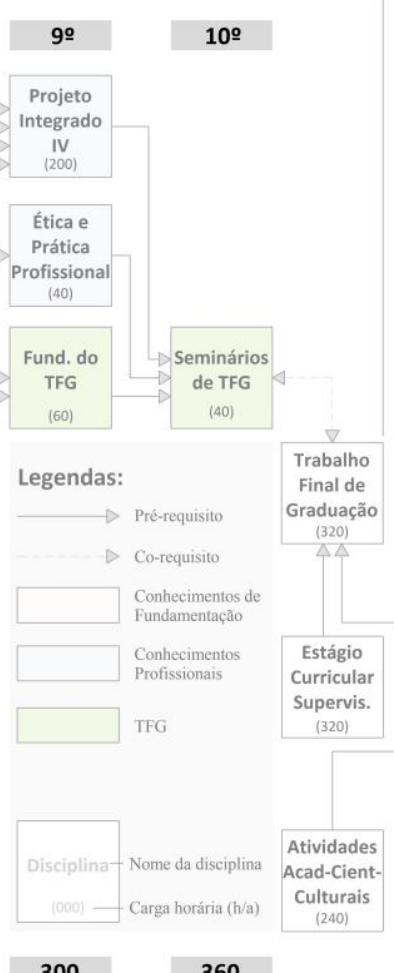

300

360

No $1^{\circ}$ período, a disciplina de Expressão e Representação Gráfica apresentará conceitos históricos sobre a evolução dos métodos e instrumentos de expressão e representação gráfica pela humanidade, incluindo BIM, RV, RA, DG, DP e PV. No $2^{\circ}$ período, o enfoque será a modelagem geométrica tridimensional, com aprofundamento das TIC's citadas e o acréscimo dos fundamentos da FD. No $3^{\circ}$ período, o enfoque será na produção de modelos BIM e aprofundamento de RV e RA. No $4^{\circ}$ período, trabalhar-se-ão modelos digitais e físicos, através do BIM, FD e PR, com ênfase em interoperabilidade, colaboração/compartilhamento. 


\section{Otimização da carga horária}

A nova matriz foi planejada para que a carga horária fosse adensada no ciclo de fundamentação (Figura 6). A diminuição gradativa projetada a partir do $5^{\circ}$ período visa a possibilidade de alocação de tempo para as novas disciplinas de projetos integrados, estágio, atividades complementares, disciplinas optativas/eletivas e o TFG.

Figura 6 - Resultados das análises comparativa das cargas horárias entre a matriz 2014-1 e 2020-1

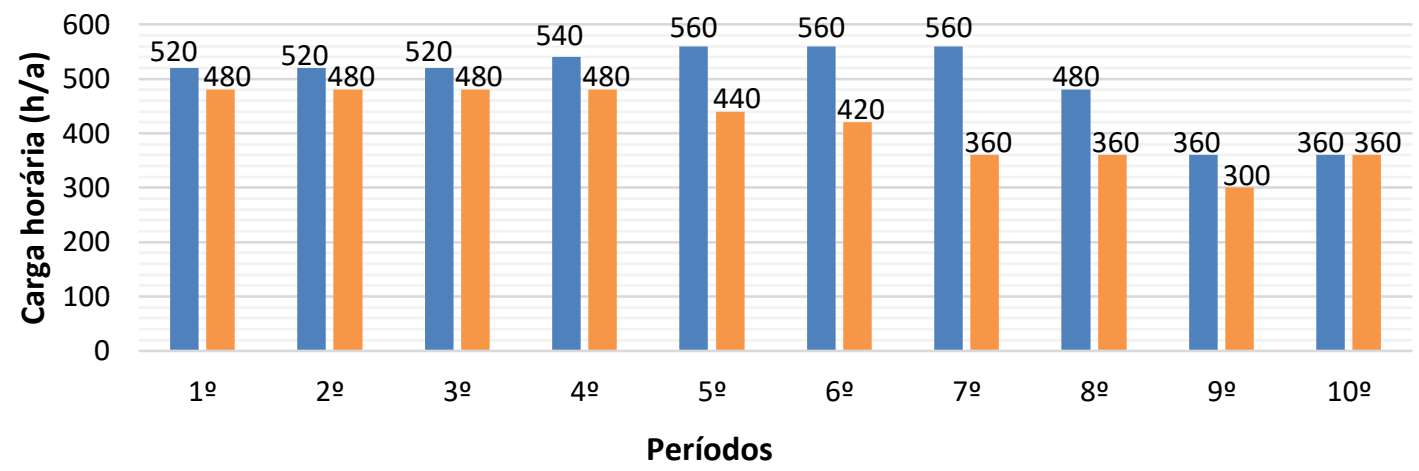

Matriz 2014-1 Matriz 2020-2

Fonte: os autores.

Os turnos também foram repensados. Na antiga matriz, o turno da manhã era de 7 hoo às $13 \mathrm{~h} 20$, enquanto o turno da tarde/noite era de $16 \mathrm{~h} 30$ às $22 \mathrm{~h} 40$. A nova proposta antecipou o fim do turno da manhã para às 12 h30 e prorrogou o início do turno da tarde/noite para às $17 \mathrm{~h} 20$, a fim de que os professores e estudantes possam se dedicar a atividades de pesquisa, extensão, criação de disciplinas optativas, entre outras atividades acadêmicas.

As demais categorias analisadas acabaram por apontar que o espaço físico para o curso era insuficiente do ponto de vista das novas realidades didático-pedagógicas. Os estudos apontados a seguir colaboraram para a reorganização dos ambientes internos, que refletiram as ideias contidas na nova matriz.

\section{Análises cibernética dos espaços físicos}

A fim de que o espaço físico refletisse o desenvolvimento das relações didáticopedagógicas do curso, Castilho (2019), em parceria com a coordenação do Curso, conduziu a pesquisa denominada como "Ensino e Produção de Arquitetura Cibernética", que propôs o desenvolvimento de um processo projetual baseado na cibernética e em princípios da teoria da informação.

Essa pesquisa foi estruturada em ciclos de desenvolvimento, a fim de, além de reproduzir o ciclo de feedback que busca aprendizagem validada, enfatizar a nãolinearidade do processo de projeto e a importância do processo em detrimento do produto. Castilho (2019) ainda assume, em consonância com os estudos de Steinhaeusser (2015), que os princípios da gestão cibernética formam a base teórica que sustenta as metodologias lean, base do processo de "desenvolvimento do cliente" (BLANK, 2013) conduzido na pesquisa.

O estudo de padrões de comunicação e controle

A cibernética representa uma abordagem unificada sobre problemas de comunicação e controle, com a preocupação explícita de compreender objetiva e matematicamente padrões de comunicação e organização (CASTILHO, 2019). O desenvolvimento de arquitetura cibernética pode ser visto na obra pioneira de Alexander (1977), “A Pattern 
Language" e "The Fun Palace", do arquiteto londrino Cedric Price (MATHEWS, 2005). De modo geral, o projeto cibernético consiste no estudo dos padrões de comunicação e controle de forma explícita e sistemática, evitando heurísticas e podendo, possivelmente, incorporar meta-heurísticas durante o processo, se assim for necessário.

Nesse sentido, a produção de centros e subcentros que reproduzissem diálogos de poder foram escrutinadas, buscando a distribuição horizontal de responsabilidade e poder. Qualidades como permeabilidade visual, acústica e física dentre ambientes também foram analisadas, assim como a adaptabilidade e a transformabilidade dos espaços.

\section{Ciclos de desenvolvimento}

O primeiro ciclo baseou-se em pesquisas de campo e pesquisas empíricas. Desenvolveram-se hipóteses iniciais e, a partir delas, coletou-se dados dos clientes professores e estudantes - para atendê-los da melhor forma possível, dentro dos limites temporais previamente estabelecidos.

A seguir, a pesquisa se aprofundou no processo ágil de desenvolvimento de cliente, conforme conceituado por Ries (2012) e Blank (2013), coletando feedback iterativamente em ciclos curtos, por meio de entrevistas com variáveis qualitativas nominais acerca do espaço físico e da proposta pedagógica do curso.

Pensados dentro de uma abordagem de design thinking (GONSALES, 2017), dados acerca da saúde; do estado de autonomia dos estudantes, das afinidades e dificuldades disciplinares e até sobre a definição de um valor para a criação de uma cultura institucional foram coletados no modelo de "sonhos e pesadelos". Essa investigação buscou destacar emoções, sentimentos, pensamentos e ideias subjetivas, para, em seguida, identificar padrões e tendências nesses dados. O resultado pode ser visto nas nuvens de palavras geradas a partir das respostas dos estudantes (Figuras 7 e 8 ).

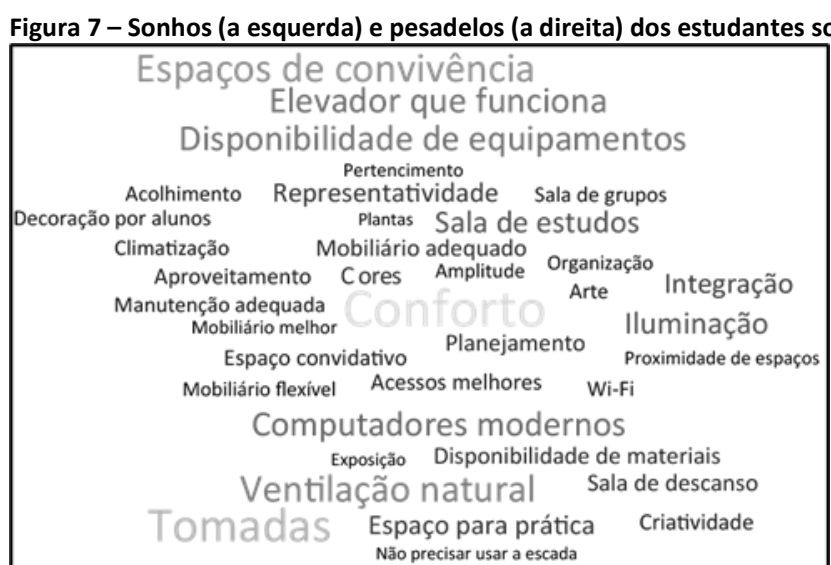

Fonte: Castilho (2019).

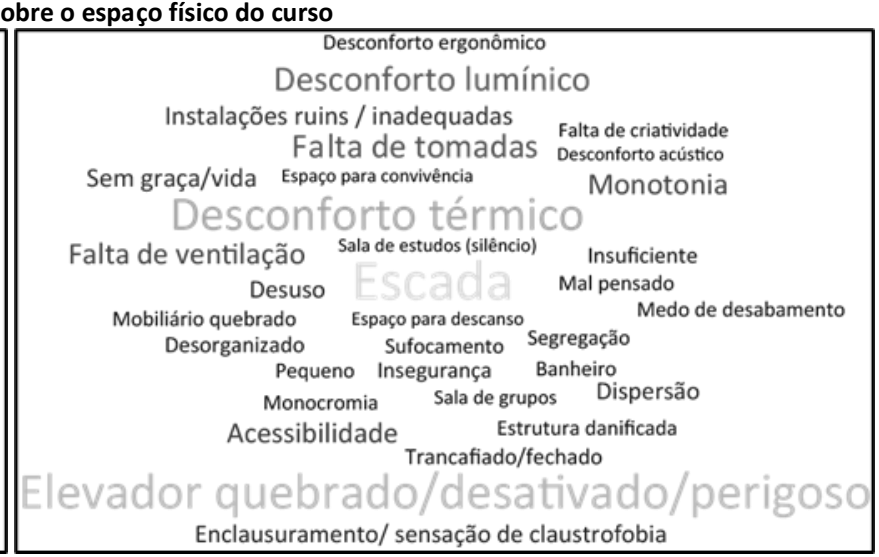
Enclausuramento/ sensação de claustrofobia

Termos representados em maior escala e luminosidade foram mais frequentes, entretanto, todas as palavras representadas no diagrama foram padrões emergentes que se revelaram nas respostas abertas. De modo geral, percebeu-se o desejo da flexibilidade e adaptabilidade dos espaços, tanto entre estudantes quanto entre professores, no que se refere ao espaço como também ao PPC. Esses insights definiram o conceito da reformulação do espaço como "Construir, reconstruir e adaptar" (Castilho, 2019). 
PEREIRA FILHO, Z. R.; SOUZA, I. C. G. de; FONSECA, R. T.

Reformulação curricular e espacial em um curso de arquitetura e urbanismo

Figura 8 - Sonhos (a esquerda) e pesadelos (a direita) dos estudantes sobre a matriz curricular do curso

\begin{tabular}{|c|c|}
\hline 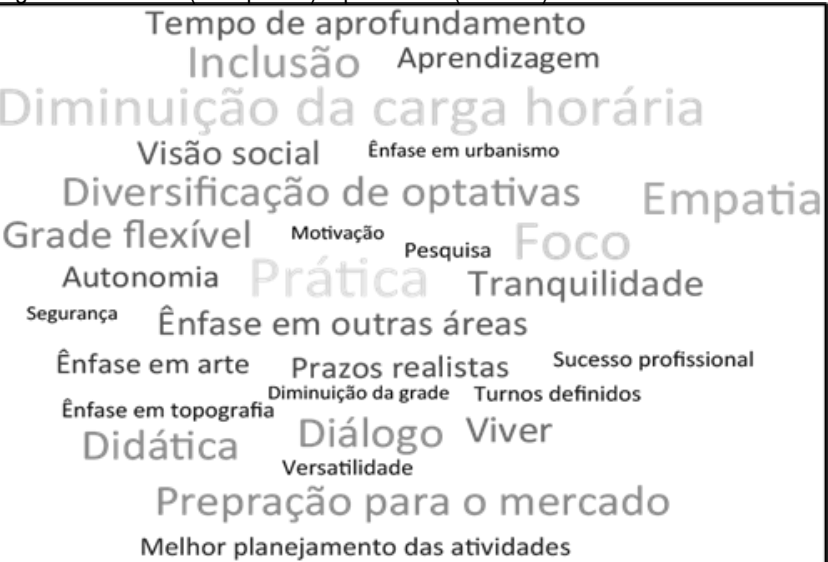 & $\begin{array}{c}\text { Incompreensão Inseguranç } \\
\text { Competição } \\
\text { Gastos Desperdício } \\
\text { Não conseguir/aprender com estágio Comparação } \\
\text { Fata de didática Professores especificos } \\
\text { Descrença no curso } \\
\text { Intransigência } \\
\text { Desistir Estresse Noites viradas Intriga } \\
\text { Topografia }\end{array}$ \\
\hline
\end{tabular}

Fonte: Castilho (2019).

Como a condução do processo projetual estava amarrada a metodologia lean (BLANK, 2013), todas as diretrizes assumidas eram tratadas como hipóteses de trabalho, efetivas até que, caso fosse provado o contrário, fossem substituídas. Seguindo essa lógica cíclica de desenvolvimento e aplicando mais atividades com professores do curso, Castilho (2019) encerrou o último ciclo aceitando a hipótese de que ateliês temáticos (Figura 9) podem funcionar como aglutinadores de interesses e núcleos de trabalho, tendo como consequência natural um agrupamento da comunidade educadora acentuado por significados, em vez de períodos ou sequências.

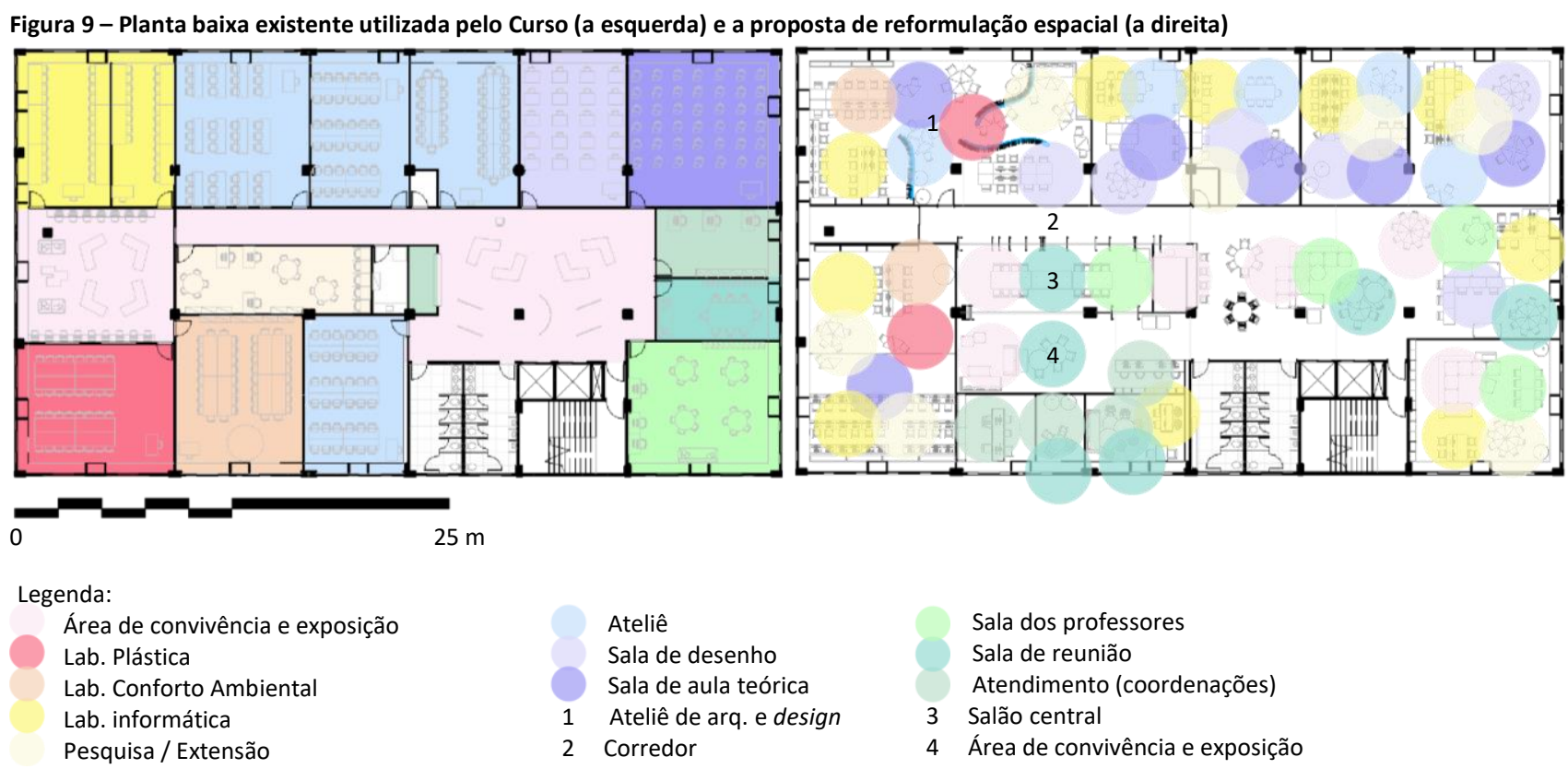

A proposta resultante da análise cibernética (a direita) traz espaços multifuncionais, em contraste com a monofuncionalidade do layout existente (a esquerda). As funções presentes dentro de um espaço delimitado ou semi-demilitado estão indicadas por círculos coloridos. De modo geral, as características do cenário a direita privilegiam a pluralidade, a diversidade e a flexibilidade dos processos ecológicos (CAPRA; LUISI, 2014), construindo "árvores de competências" (LÉVY, 2010) individuais, que permitem combinações fartas o suficiente para proporcionar a reinvenção da identidade profissional do arquiteto e urbanista. 
O modelo organizacional do espaço obtido nesse processo trouxe laboratórios e ateliês mais integrados; espaços de descanso/silêncio; áreas de convivência vivas e povoadas, com propósito e utilidade; copa integrada; e espaço central iluminado (3) e completamente transformável, podendo formar um grande salão que integra regiões (2), (3) e (4). O ateliê integrado de arquitetura e design (1) é um espaço para experimentação e maturação dos princípios de gestalt.

Considerando-se a primazia dada a análise binária e qualitativa das relações intra e inter ambientais, resultados práticos como o núcleo central altamente transformável e flexível não foram efeitos meramente simbólicos, mas alinhamentos funcionais aos diálogos de poder revistos no PPC alcançados.

\section{A reformulação espacial}

A partir da convergência dos resultados produzidos pelas pesquisas realizadas, constatou-se que algumas ações, no âmbito do espaço físico recém inaugurado, precisavam acontecer de imediato para atender as demandas da nova matriz. Essas adequações aconteceram em 2019 (Figura 10).

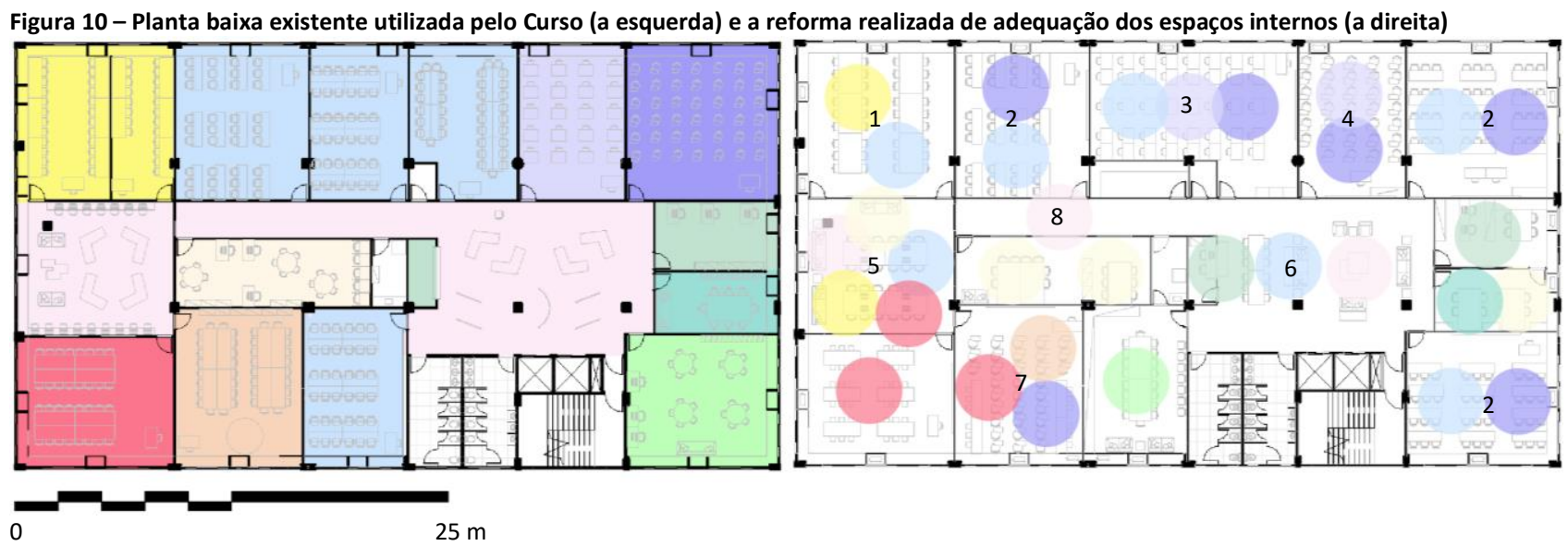

Legenda:

Área de convivência e exposição

Lab. Plástica

Lab. Conforto Ambiental (7)

Lab. informática (1)

Pesquisa / Extensão
Ateliê

Sala de desenho

Sala de aula teórica

8 Corredor expositivo
Sala dos professores

Sala de reunião

Atendimento (coordenações)

5 Espaço de convivência multiuso

6 Área de convivência e exposição

Fonte: Adaptado de Castilho (2019).

É possível observar no projeto de reforma (a direita), ainda que de forma pontual, o surgimento de espaços multifuncionais e novos arranjos dos mobiliários existentes, em contraste com a monofuncionalidade da proposta anterior (a esquerda). Houve uma nova distribuição de funções nos ambientes e algumas pequenas intervenções físicas, com a demolição de paredes, aberturas de portas e mudança de mobiliários e equipamentos.

Os laboratórios de informática (1) se integraram, tornando-se, também, ateliê. Os ateliês (2) ganharam condições de também serem utilizados como salas de aulas teóricas. A sala de desenho (3) ganhou mais espaço e novas funções, ateliê e sala de aula teórica. A sala de aula teórica (4) ganhou novos mobiliários, o que possibilitou o seu uso para atividades de desenho. O espaço de convivência e exposição (5), ganhou mais usos como, ateliê, laboratório de informática, pesquisa/extensão e laboratório de plástica. 0 espaço de convivência e exposição (6) também pode ser utilizado como ateliê. Por 
último, o laboratório de conforto (7), obteve uso como laboratório de plástica e sala de aula teórica.

\section{Conclusão}

Esse artigo expõe a reformulação curricular e espacial realizadas no curso de Arquitetura e Urbanismo do Instituto Federal Fluminense (IFF) e a colaboração de duas pesquisas nesse processo. A primeira delas desenvolveu um método de análise de componentes curriculares com objetivo de simular cenários possíveis do novo currículo, munindo os debates e reflexões acerca desse tema, enquanto a segunda aplicou conceitos cibernéticos para revelar e atuar sobre as relações de poder materializadas no espaço físico do curso. Os principais conceitos que uniram estes estudos foram a interdisciplinaridade, integração, colaboração e a tecnologia. A relação interdisciplinar e tecnológica, inerente ao nosso momento histórico, rompe com a lógica particionada das tradicionais práticas didático-pedagógicas e, consequentemente, salas de aula e laboratórios tradicionais.

Os resultados das análises das disciplinas apontaram diversas possibilidades de implementação das TIC's, interdisciplinaridade, otimização da carga horária, entre outros parâmetros. Para Barison (2015) a associação entre as TIC's e tais parâmetros se apresenta como a alternativa mais adequada, quando distribuídos ao longo do currículo. Porém, essas possibilidades não foram implementadas por completo devido ao desconforto com os conceitos supracitados nas análises por parte da maioria dos professores e, também, por não haver consenso nas discussões decisórias de que a evolução das técnicas envolvidas no processo de projeto e fabricação sejam fundamentais a formação acadêmica, já que há a certeza de sua breve obsolescência.

A pesquisa sobre reformulação dos espaços físicos do curso propôs ambientes multifuncionais, mais alinhados as relações didático-pedagógicas do novo PPC. A proposta espacial alcançada viabilizou a implementação dos resultados obtidos na primeira pesquisa e colaboraram para o planejamento da transição curricular. Novas intervenções deverão ser executadas para que o espaço continue se desenvolvendo em harmonia com as propostas relatadas.

A partir da associação das pesquisas apresentadas, foi possível perceber que, mesmo sob perspectivas diferentes, os resultados se entrelaçaram e corroboraram um ao outro. Quanto mais as análises dos componentes curriculares da matriz aprofundavamse, mais assertivas eram as decisões de adequação dos espaços físicos e suas respectivas instalações. Conclui-se que os resultados apresentados se demonstram significativos e capazes de apoiar as necessidades da reformulação curricular do curso, além de estimularem outras iniciativas que busquem por métodos e instrumentos de suporte ao ensino integrado com o uso de novas tecnologias.

\section{Agradecimentos}

Ao CNPq pelo apoio de Bolsas de Iniciação Científica PIBITI. Aos coordenadores que atuaram ao longo dos anos e colaboraram, cada um à sua maneira, para o êxito da reformulação curricular. Aos demais professores do curso, em especial, a professora Silvana Monteiro de Castro, coordenadora adjunta entre os anos de 2018 e 2021 e a professora Danielly Cozer Aliprandi que coorientou uma das pesquisas desse artigo. Ao Centro Acadêmico Regina Aquino (C.A.R.A), estudantes e bolsistas das pesquisas que atuaram para essa construção coletiva.

\section{Referências}

AGOGUÉ, M. et. al. The impacts of examples on creative design: explaining fixation and stimulation effects. Journal of Creative Behavior. v. 48, n. 1., p. 1-12. 2013. DOI: https://doi.org/10.1002/jocb.37 
PEREIRA FILHO, Z. R.; SOUZA, I. C. G. de; FONSECA, R. T.

Reformulação curricular e espacial em um curso de arquitetura e urbanismo

ALEXANDER, C. A pattern Language: town, buildings, construction. New York: Oxford University Press, 1977. 1171p.

ALLEN, J. B. Parametric Master Planning. Youtube, postador por “EvolveLAB”, 29 mar. 2018. (40mino6s).

Disponível em: https://www.youtube.com/watch?v=xq6yKyauu-o\&t=181s. Acesso em: 26 mai. 2020.

BARAN, P. On Distributed Communications, Memorandum. Santa Monica, Calif.: RAND Corporation, 1964. DOI: https://doi.org/10.7249/RM3420

BARISON, M. B. Introdução de Modelagem da Informação da Construção (BIM) no Currículo: uma contribuição para a formação do projetista. 2015. 387 p. Tese (Doutorado em Engenharia da Construção Civil) - Escola Politécnica, Departamento de Engenharia de Construção Civil da Universidade de São Paulo, São Paulo. DOI: https://doi.org/10.11606/T.3.2016.tde-21032016-101815

BLANK, S. G. The four steps to the epiphany: successful strategies for products that win. K \& S Ranch, 2013. Edição do Kindle.

BRAIDA, F. et al. (Organizadores). 101 conceitos de arquitetura e urbanismo na era digital. São Paulo: ProBooks, 2016.

CAPRA, F.; LUISI, P. L. A visão sistêmica da vida: uma concepção unificada e suas implicações filosóficas, políticas, sociais e econômicas. São Paulo: Cultrix, 2014. 615p.

CASTILHO, I. G. S. Ensino e Produção de Arquitetura Cibernética. 2019. 196 f.: il. color. Trabalho Final de Graduação Arquitetura e Urbanismo, Instituto Federal de Educação, Ciência e Tecnologia Fluminense.

CELANI, M. G. C. et al. A gramática da forma como metodologia de análise e síntese em arquitetura. In: Conexão Comunicação e Cultura, UCS, Caxias do Sul, v. 5, n. 10, p. 180-197, jul./dez. 2006. Disponível em: http://www.ucs.br/etc/revistas/index.php/conexao/article/view/222/213. Acesso em: 3 jun. 2020.

CHECCUCCI, E. S; AMORIM, A. L. Método para análise de componentes curriculares: identificando interfaces entre um curso de graduação e BIM. PARC Pesquisa em Arquitetura e Construção, Campinas, v. 5, n. 1, p. 6-17, jan./jun. 2014graduação e BIM. PARC Pesquisa em Arquitetura e Construção, Campinas, v. 5, n. 1, p. 6-17, jan./jun. 2014. DOI: https://doi.org/10.20396/parc.v5i1.8634540

COLI, J. S. Alberti e suas igrejas: os caminhos da harmonia. Discurso, [S. I.], n. 14, p. 159-180, 1983. DOI: https://doi.org/10.11606/issn.2318-8863.discurso.1983.37908

DE KESTELIER, X; BUSWELL, R. A Digital Design Environment for Large Scale Rapid Manufacturing. In: ACADIA o9: Building a Better Tomorrow. 2009. Anais... Illinois, Chicago: Proceedings of the 29th Annual Conference of the Association for Computer Aided Design in Architecture (ACADIA), 22-25 out. de 2009. p. 201-208.

FAROOQ, M. U. et al. A Review on Internet of Things. International Journal of Computer Applications. v. 113, n. 1, mar. 2015. DOI: https://doi.org/10.5120/19787-1571

GONSALES, P. Design thinking e a ritualização de boas práticas educativas. Revisão de Thatyane Furtado. São Paulo: Instituto Educadigital, 2017. 88p.

HANAFIN, S; PITTS, G; DATTA, S. Non-Deterministic Exploration through Parametric Design. International Journal of Architectural Computing. v. 7, n. 4, p. 605-622, 2009. DOI: https://doi.org/10.1260/1478-0771.7.4.605

HÖLLERER, T. H; FEINER, S. K. Mobile Augmented Reality. In: KARIMI, H; HAMMAD, A. Telegeoinformatics: Location-Based Computing and Services. Taylor \& Francis, 2004.

JAPIASSÚ, H. Interdisciplinaridade e patologia do saber. Rio de Janeiro: Imago Editora, 1974.

JOHNSON, S. De onde vêm as boas ideias: uma história natural da inovação. Rio de Janeiro: Zahar, 2011. Edição do Kindle. 
KANG et al. A Roundtable Discussion: Defining Urban Data Science. Environment and Planning B: Urban Analytics and City Science. v. 46, n.9, p. 1756-1768, nov. 2019. DOI: https://doi.org/10.1177/2399808319882826

KOLAREVIC, B. Architecture in the Digital Age: Design and Manufacturing. Taylor \& Francis, 2003,320 p.

LEAL, B. M. F.; SALGADO, M. S. Propostas de incorporação de BIM no curso de Arquitetura e Urbanismo. PARC Pesquisa em Arquitetura e Construção, Campinas, SP, v. 10, p. e019025, 25 jul. 2019. DOI: https://doi.org/10.20396/parc.v10io.8653676

LÉVY, P. As Tecnologias da Inteligência: o futuro do pensamento na era da informática. São Paulo: Editora 34, 2004. LÉVY, P. Cibercultura. São Paulo: Editora 34, 2010.

MATHEWS, S. The Fun Palace: Cedric Price's experiment in architecture and technology. 2005. Technoetic Arts, v. 3 , n. 2, p. 73-91. DOI: https://doi.org/10.1386/tear.3.2.73/1

MORI, L. Especialista: pensamento e colaboração são mais importantes que matemática. UOL Educação, 09 mar. 2019. Disponível em: https://educacao.uol.com.br/noticias/bbc/2019/03/og/pensamento-critico-formulas-dematematica-educacao-do-seculo-21.htm. Acesso em: 04 jun. 2021.

PIRES, J. de F.; PEREIRA, A. T. C.; GONÇALVES, A. TAXONOMIAS DE GEOMETRIA DA ARQUITETURA CONTEMPORÂNEA: UMA ABORDAGEM DIDÁTICA AO ENSINO DA MODELAGEM PARAMÉTRICA NA ARQUITETURA. Gestão \& Tecnologia de Projetos, [S. I.], v. 12, n. 3, p. 27-46, 2017. DOI: https://doi.org/10.11606/gtp.v12i3.133954

PUPO, R. T. Ensino da prototipagem rápida e fabricação digital para arquitetura e construção no Brasil: definições e estado da arte. PARC Pesquisa em Arquitetura e Construção, v. 1, n. 3, p. 80-98, 1 nov. 2008. DOI: https://doi.org/10.20396/parc.v1i3.8634511

RIES, E. A startup enxuta: como os empreendedores atuais utilizam a inovação contínua para criar empresas extremamente bem-sucedidas. São Paulo: Lua de Papel, 2012. Edição do Kindle.

SEDREZ, M. One building, one detail: entrevista com o arquiteto Pieter Schreurs, Entrevista, São Paulo, ano 16, n. 064.04, Vitruvius, nov. 2015.

SENSEABLE CITY LAB (SCL). Position Opening. Massachusetts: MIT, 2020. Disponível em: < http://senseabledb.mit.edu/system/positions/pdfs/000/000/004/original/SCL_Data_Viz_UX_UI_Spec_Job_Descriptio n.pdf?1572550401>. Acesso em: 24 abr. 2020.

STEINHAEUSSER, T. et al. Management Cybernetics as a Theoretical Basis for Lean Construction Thinking. Lean Construction Jornal, 2015. p. 01-14. Disponível em:

https://www.leanconstruction.org/media/docs//cj/2015/LCJ_14_005.pdf. Acesso em: 25 jan. 2019.

\footnotetext{
${ }^{1}$ Zander Ribeiro Pereira Filho

Arquiteto e Urbanista. Doutorando no Programa de Pós-graduação em Urbanismo da Universidade Federal do Rio de Janeiro. Professor do Instituto Federal Fluminense. Endereço postal: Rua Doutor Siqueira, 182/183, Parque Tamandaré, Campos dos Goytacazes, RJ - Brasil. CEP 28030-130.
}

\section{${ }^{2}$ Isabela Castilho Gomes de Souza}

Arquiteta e Urbanista. Pesquisadora no Instituto Federal Fluminense. Endereço postal: Rua Doutor Siqueira, 182/183, Parque Tamandaré, Campos dos Goytacazes, RJ - Brasil. CEP 28030-130.

\section{${ }^{3}$ Rodrigo Tannus Fonseca}

Arquiteto e Urbanista pelo Instituto Federal Fluminense. Pós graduado em Arquitetura da Cidade: suas demandas e tecnologias pelo Instituto Federal Fluminense. Endereço postal: Rua Doutor Siqueira, 182/183, Parque Tamandaré, Campos dos Goytacazes, RJ - Brasil. CEP 28030-130. 